\title{
ORTHOPAEDIC EMERGENCY CASES AT HASAN SADIKIN HOSPITAL BANDUNG CAUSED BY TRADITIONAL BONE SETTER PRACTICE
}

\author{
Hantonius $^{1 *}$, Hermawan Nagar Rasyid ${ }^{2}$, Gibran Tristan Alpharian ${ }^{2}$ \\ ${ }^{1}$ Resident of Orthopaedics and Traumatology Department, Faculty of Medicine Universitas \\ Padjadjaran/Dr. Hasan Sadikin Hospital, Bandung \\ ${ }^{2}$ Staff of Orthopaedics and Traumatology Department, Faculty of Medicine Universitas \\ Padjadjaran/Dr. Hasan Sadikin Hospital, Bandung \\ *Corresponding Author: Hantonius, Resident of Orthopaedics and Traumatology Department \\ Faculty of Medicine Universitas Padjadjaran/Dr. Hasan Sadikin Hospital, Bandung, Jl. \\ Pasteur No. 38 Bandung, Jawa Barat 40161. \\ E-mail: dedogtor@gmail.com
}

\begin{abstract}
ABSTRAK
Praktik pengobatan tulang tradisional masih sering ditemukan di negara berkembang, termasuk Indonesia. Praktisi tradisional ini melakukan "pengobatan" tanpa dilandasi pengetahuan medis. Meskipun di kalangan awam terdapat anggapan bahwa pengobatan tulang tradisional memberikan hasil yang baik, namun sesungguhnya angka kegagalan dan komplikasi yang ditimbulkan oleh pengobatan tradisional tersebut tinggi.

Tujuan penelitian ini adalah melaporkan kasus kegawatdaruratan di bidang orthopaedi yang disebabkan oleh komplikasi dari praktik pengobatan tulang tradisional. Jenis penelitian ini adalah observasional deskriptif, terdapat 36 pasien dengan komplikasi setelah pengobatan oleh praktisi pengobatan tulang tradisional yang dibawa ke Instalasi Gawat Darurat RS Hasan Sadikin antara 1 Januari 2015 - 31 Agustus 2017.

Di antara kasus emergensi di RS Hasan Sadikin yang disebabkan oleh praktisi pengobatan tulang tradisional, sindroma kompartemen dan gangren merupakan komplikasi yang paling sering terjadi. Terdapat dua puluh pasien (56\%) dengan luka terinfeksi dan sindroma kompartemen yang berhasil dilakukan tindakan operasi, tiga belas (36\%) pasien dengan gangren pada ektremitas yang diamputasi, dan tiga pasien (8\%) pasien dengan kegagalan multi organ meninggal dunia. Sebanyak dua belas persen dari seluruh amputasi yang dilakukan di RS Hasan Sadikin berhubungan dengan praktik pengobatan tulang tradisional.

Hasil penelitian ini menunjukkan bahwa komplikasi yang ditimbulkan oleh praktik pengobatan tulang tradisional dapat menimbulkan morbiditas yang tinggi seperti kehilangan anggota badan bahkan mortalitas.
\end{abstract}

Kata kunci: Kasus emergensi orthopaedi, praktik pengobatan tulang tradisional, neglected fracture

\begin{abstract}
Traditional bone setting is common in developing nations. The practitioners are barely educated and rely so much on experience. Although they are popular in public, traditional bone setter are known in hospital practice for their failures and complications which present to hospitals for remediation.

The purpose of the study is to report the orthopaedic emergency cases caused by the practice of traditional bone setter. This was an observational descriptive study, 36 patients with complications after practice of traditional bone setters and subsequently presented to emergency ward in Hasan Sadikin Hospital between $1^{\text {st }}$ January 2015 and $31^{\text {st }}$ August 2017 were evaluated.

Among emergecy orthopaedic cases at Hasan Sadikin Hospital caused by bonesetter practice, compartment syndrome and gangrene are the most common complications occured.
\end{abstract}


Twenty patients $(56 \%)$ with infected wound and compartment syndrome had successful operation., thirteen patients (36\%) with gangrene of the extremities had amputations, and three patients (11\%) with multiple organ failure died. Twelve percent of amputations in our centre were related to bonesetter practice.

The result of this study indicates that traditional bone setters practice may caused patients to develop complications, lose their limbs even lives due to inappropriate treatments. Keywords: Orthopaedic emergency cases, traditional bone setter practice, neglected fracture.

\section{PENDAHULUAN}

Praktik pengobatan tulang tradisional masih sering ditemukan di negara berkembang, termasuk Indonesia. Praktisi pengobatan tulang tradisional ini melakukan "pengobatan” tanpa memiliki pengetahuan mengenai anatomi, fisiologi, pengetahuan dasar mengenai investigasi penyakit dan perawatan luka. ${ }^{1}$

Sebagian besar pasien yang datang ke praktik pengobatan tulang tradisional adalah pasien golongan sosial ekonomi menengah ke bawah meskipun tidak menutup kemungkinan dari kalangan sosial ekonomi yang lain. Hal ini mungkin disebabkan oleh kepercayaan tradisional, lebih mudahnya akses untuk bertemu praktisi pengobatan tulang tradisional dan biaya berobat yang dianggap "lebih murah". 1

Meskipun terdapat persepsi di kalangan awam bahwa pengobatan tradisional memberikan hasil yang baik, namun pada sesungguhnya angka kegagalan dan komplikasi yang ditimbulkan oleh pengobatan tradisional tersebut tinggi. Penelitian Udosen et al di Nigeria melaporkan bahwa komplikasi yang dijumpai dapat menimbulkan morbiditas yang tinggi seperti kehilangan anggota badan, atau bahkan mortalitas. ${ }^{2}$

Tujuan dari penelitian ini adalah melaporkan kasus kegawatdaruratan di bidang orthopaedi yang disebabkan oleh komplikasi dari praktik pengobatan tulang tradisional.

Penelitian ini menggunakan metode observasional deskriptif, terhadap semua pasien dengan penyakit muskuloskeletal yang sudah ditangani oleh praktisi tradisional kemudian dibawa ke Instalasi Gawat Darurat Rumah Sakit Hasan Sadikin Bandung.

\section{LAPORAN KASUS}

Pada laporan kasus ini, data yang digunakan merupakan data primer yang didapat dari 36 pasien yang datang ke Instalasi Gawat Darurat Rumah Sakit Hasan Sadikin dengan komplikasi setelah berobat ke berbagai praktisi pengobatan tulang tradisional yang ada di Jawa Barat, Indonesia antara 1 Januari 2015 sampai 31 Desember 2017. 
Laporan Kasus

Vol 7 No. 1, April 2018

ISSN 2460-8742

http://journal.unair.ac.id/ORTHO@journal-orthopaedi-and-traumatology-surabaya-media-104.html

Berdasarkan jenis kelamin, terdapat 28 pasien laki-laki (77\%) dan 8 perempuan (23\%). Dua puluh lima pasien (69\%) merupakan kelompok dewasa muda dengan usia antara 21-40 tahun.

Pekerjaan pasien bervariasi, sebagian besar merupakan buruh industri dengan jumlah 14 orang (41\%), pembantu rumah tangga 9 orang (25\%), supir 4 orang (11\%), pelajar 3 orang (8\%) dan yang lainnya (15\%). Tingkat pendidikan pasien yaitu, Sekolah Dasar 4 orang (11 \%), Sekolah Menengah Pertama 11 orang (31\%), and Sekolah Menengah Atas 21 orang (58\%) (Tabel $1)$.

Tabel 1. Karakteristik pasien

\begin{tabular}{lc}
\hline \multicolumn{1}{c}{ Usia (tahun) } & Total \\
\hline$<20$ & $4(11 \%)$ \\
$20-40$ & $21(58 \%)$ \\
$40-60$ & $9(25 \%)$ \\
$>60$ & $2(6 \%)$ \\
\hline \multicolumn{1}{c}{ Pekerjaan } & Total \\
\hline Buruh industri & $14(39 \%)$ \\
Pembantu rumah tangga & $9(25 \%)$ \\
Supir & $4(11 \%)$ \\
Pelajar & $3(8 \%)$ \\
Lainnya & $6(17 \%)$ \\
\hline \multicolumn{2}{c}{ Pendidikan } \\
Sekolah Dasar & Total \\
Sekolah Menengah Pertama & $11(11 \%)$ \\
Sekolah Menengah Atas & $21(58 \%)$ \\
\hline
\end{tabular}

Sebagian besar pasien datang ke praktik pengobatan tulang tradisional dengan riwayat cedera muskuloskeletal (83\%) seperti patah tulang terbuka, patah tulang tertutup, dan luka terbuka; namun ada juga pasien dengan infeksi (11\%), keganasan (3\%) dan penyakit kongenital (3\%) (Tabel 3).

Tatalaksana yang dilakukan oleh praktisi tradisional mencakup pemberian ramuan herbal yang diaplikasikan ke kulit, pengurutan, perenggangan dan pembebatan tulang yang patah dengan bambu atau tongkat kayu dan diikat dengan kain atau tali rafia.

Ditemukan dua puluh pasien (56\%) dengan luka yang terinfeksi dan sindroma kompartemen berhasil dioperasi, baik dengan fiksasi eksternal, debridemen atau fasiotomi. Tiga belas pasien (36\%) dengan gangren pada extremitas dilakukan operasi amputasi. Tiga pasien (8\%) dengan kegagalan multi organ meninggal dunia (Tabel 2).

\section{DISKUSI}

Praktik pengobatan tulang tradisional masih sering ditemukan di sebagian besar negara berkembang, termasuk Indonesia, tanpa regulasi dan pengawasan yang memadai dari pemerintah. $^{3}$ 
Laporan Kasus

Vol 7 No. 1, April 2018

ISSN 2460-8742

http://journal.unair.ac.id/ORTHO@journal-orthopaedi-and-traumatology-surabaya-media-104.html

Pada penelitian ini, sebagian besar pasien adalah laki-laki (77\%), hasil ini sesuai dengan penelitian oleh Olalorun yang menyatakan bahwa laki-laki sebagian besar bekerja dan memiliki mobilitas yang lebih tinggi, sehingga memiliki risiko lebih tinggi untuk mengalami cedera. ${ }^{4}$

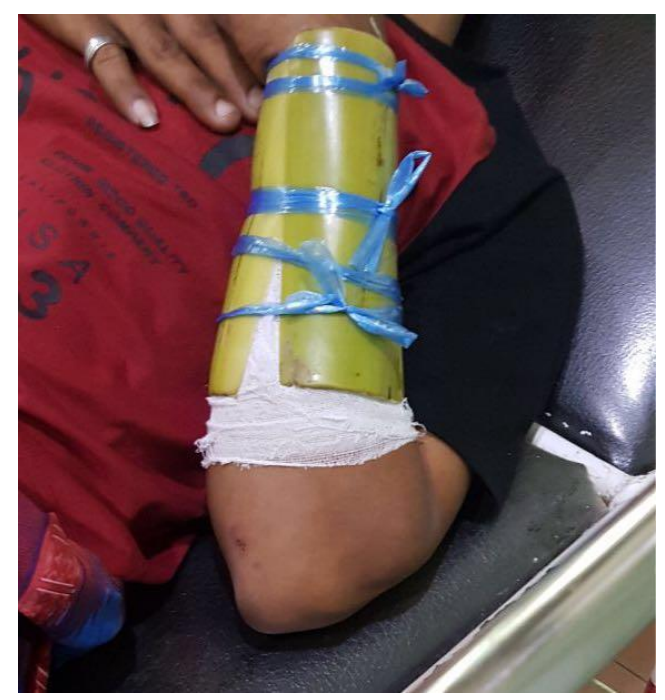

Gambar 1. Pembebatan dengan menggunakan kayu dan tali rafia

Berdasarkan usia, sebagian besar pasien berusia 21-40 tahun (69\%). Mereka merupakan pasien dewasa muda dengan usia produktif, rata-rata mereka bekerja sebagai buruh $(41 \%)$ dan pembantu (25\%) dengan tingkat pendidikan dan keadaan ekonomi yang rendah. Hal ini tergambarkan pada serial kasus ini, dimana semua pasien tidak mengenyam pendidikan tinggi. Ketika mereka sakit, mereka tidak bisa bekerja sehingga mengakibatkan hilangnya pendapatan untuk satu keluarga. ${ }^{4}$

Kebanyakan kasus yang kami temukan, merupakan kasus cedera muskuloskeletal (83\%) berupa patah tulang terbuka (44\%), patah tulang tertutup (31\%) dan luka terbuka (8\%)

Tabel 2. Tatalaksana, Morbiditas dan Mortalitas pasien.

\begin{tabular}{|c|c|}
\hline Tatalaksana & Total \\
\hline $\begin{array}{l}\text { Debridemen, Fasiotomi } \\
\text { dan Fiksasi Eksterna }\end{array}$ & $20(56 \%)$ \\
\hline Amputasi & $13(36 \%)$ \\
\hline Resusitasi & $3(8 \%)$ \\
\hline $\begin{array}{l}\text { Morbiditas dan } \\
\text { Mortalitas }\end{array}$ & Total \\
\hline Disabilitas & $13(36 \%)$ \\
\hline Meninggal dunia & $3(8 \%)$ \\
\hline
\end{tabular}

Hal ini serupa dengan beberapa publikasi sebelumnya yang menemukan bahwa kasus trauma muskuloskeletal menjadi penyebab utama yang membawa pasien berobat ke praktisi pengobatan tulang tradisional di seluruh dunia. ${ }^{5}$ Namun, pada penelitian ini, ditemukan juga kasus kaki diabetik (11\%), osteosarkoma humerus proksimal (3\%) dan clubfoot (3\%).

Kasus trauma muskuloskeletal ditatalaksana oleh praktisi pengobatan tulang tradisional dengan pengurutan, perenggangan dan pembebatan tulang yang patah dengan bambu atau tongkat 
Laporan Kasus

Vol 7 No. 1, April 2018

ISSN 2460-8742

http://journal.unair.ac.id/ORTHO@journal-orthopaedi-and-traumatology-surabaya-media-104.html

kayu dan diikat dengan kain atau tali

"rafia".

Tabel 3. Penyakit awal dan komplikasi

\begin{tabular}{lclc}
\hline \multicolumn{1}{c}{ Penyakit awal } & Total & \multicolumn{1}{c}{$\begin{array}{c}\text { Komplikasi setelah } \\
\text { berobat ke praktisi } \\
\text { tradisional }\end{array}$} & Total \\
\hline Patah tulang terbuka & $16(44 \%)$ & $\begin{array}{l}\text { Sindroma kompartemen } \\
\text { Gangren }\end{array}$ & $8(22.2 \%)$ \\
& & Kegagalan multi organ & $7(19.4 \%)$ \\
& $11(31 \%)$ & Sindroma kompartemen & $1(2.7 \%)$ \\
\hline Patah tulang tertutup & & Gangren & $8(22.2 \%)$ \\
& $4(11 \%)$ & Luka terinfeksi & $3(8.3 \%)$ \\
\hline Infeksi & & Gangren & $2(5.4 \%)$ \\
& & Kegagalan multi organ & $1(2.7 \%)$ \\
\hline Luka terbuka & $3(8 \%)$ & Luka terinfeksi & $1(2.7 \%)$ \\
\hline Keganasan & & Gangren & $2(5.4 \%)$ \\
\hline Penyakit Kongenital & $1(3 \%)$ & Kegagalan multi organ & $1(2.7 \%)$ \\
\hline
\end{tabular}

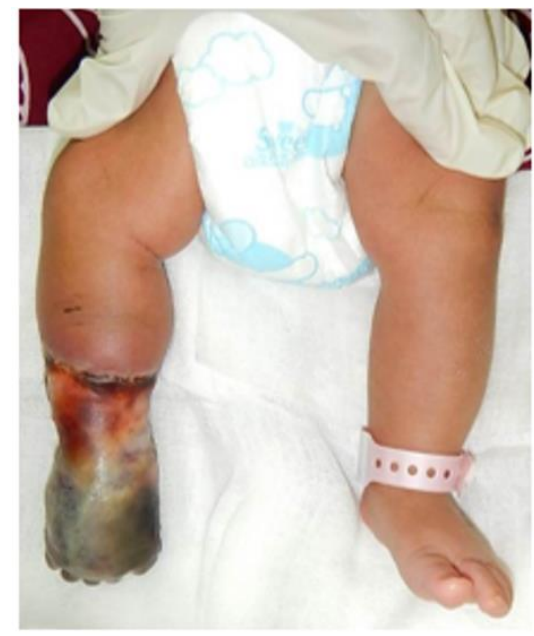

Gambar 2. Bayi usia 1 bulan dengan gangren di kaki setelah pembebatan erat menggunakan kain untuk tatalaksana clubfoot
Luka terbuka mendapat perlakuan berupa pemberian ramuan herbal yang diaplikasikan ke luka, pada satu kasus luka terbuka dengan cedera pembuluh darah, salah satu praktisi pengobatan tulang tradisional melakukan pembebatan dengan sangat ketat untuk mencoba menghentikan perdarahan. Hal ini mengakibatkan kondisi iskemia bahkan gangren pada ekstremitas. ${ }^{6}$

Kami menemukan satu pasien dengan osteosarkoma humerus proksimal yang diurut dan menyebabkan perdarahan dari massa tumor. Pasien datang ke rumah sakit dalam kondisi 
anemia dan sepsis akibat luka yang terinfeksi. Pasien tersebut akhirnya meninggal karena sepsis berat dan disertai kegagalan multi organ.

Selain itu, terdapat satu kasus kelainan kongenital, bayi usia 1 bulan dengan clubfoot yang dibebat erat menggunakan kain untuk mengkoreksi deformitas. Setelah tatalaksana selama dua minggu, kaki bayi membengkak kemudian menghitam. Orangtua bayi tersebut membawa pasien ke rumah sakit setelah timbul gangren pada ektremitas, sehingga harus dilakukan amputasi transtibial.

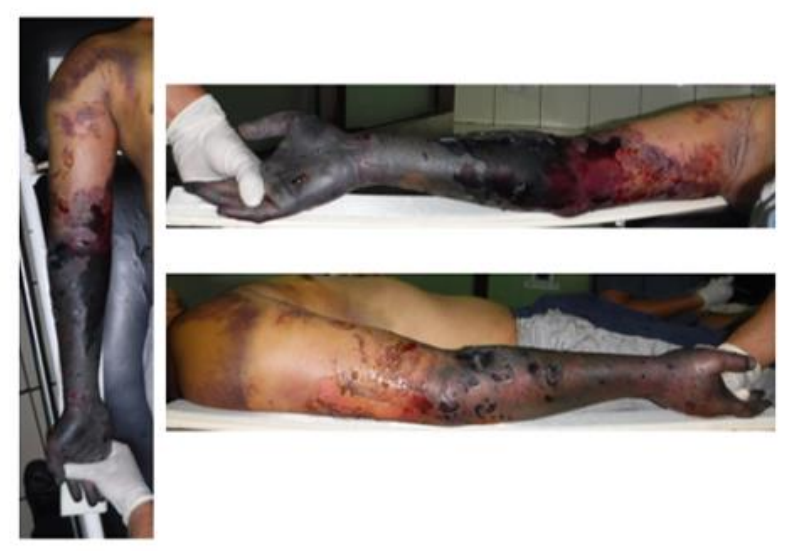

Gambar 3. Laki-laki usia 49 tahun dengan gangren pada ekstremitas setelah dilakukan perenggangan dan pembebatan tulang yang patah menggunakan kayu dan kain

Sebanyak $12 \%$ dari total operasi amputasi yang dilakukan di Rumah Sakit Hasan Sadikin selama periode Januari 2015-Desember 2017 berhubungan dengan gangren dan komplikasi akibat tatalaksana pengobatan tulang tradisional. Terdapat penelitian yang serupa oleh Onuminya et al di Nigeria dengan hasil $15 \%$ pasien yang diamputasi berhubungan dengan tatalaksana oleh pengobatan tulang tradisional. ${ }^{7}$

Sulit untuk mengetahui secara pasti penyebab utama terjadinya iskemia dan gangren karena kita tidak mengetahui secara pasti tingkat keparahan serta mekanisme cedera dari pasien sebelum mereka datang ke pengobatan tulang tradisional. Iskemia bisa terjadi karena terjadi cedera pembuluh utama yang disebabkan oleh cedera awal, namun iskemia bisa juga disebabkan oleh sindroma kompartemen karena hematoma dan inflamasi dari fraktur. ${ }^{8}$

Keadaan iskemia karena sindroma kompartemen tersebut dapat juga disebabkan oleh pembebatan yang erat yang biasa dilakukan oleh praktisi pengobatan tulang tradisional. ${ }^{8}$

Amputasi harus dilakukan pada untuk mengontrol infeksi dan mengatasi keadaan sepsis, namun terdapat beberapa kasus dimana pasien datang dengan kegagalan multi organ sehingga pasien tidak dapat diselamatkan dan meninggal. ${ }^{8}$ 


\section{KESIMPULAN DAN SARAN}

Di antara kasus emergensi di Rumah Sakit Hasan Sadikin Bandung yang disebabkan oleh praktisi pengobatan tulang tradisional, sindroma kompartemen dan gangren merupakan komplikasi yang paling sering terjadi dan menyebabkan morbiditas terhadap pasien.

Tindakan amputasi seringkali harus dilakukan untuk mengontrol infeksi dan menyelamatkan nyawa pasien. ${ }^{9}$ Hilangnya anggota badan akan menimbulkan disabilitas pada pasien dan mempengaruhi keadaan ekonomi keluarga terutama pada sebagian besar pasien dengan usia produktif. ${ }^{10}$

Hasil penelitian ini menunjukkan bahwa komplikasi yang ditimbulkan oleh praktik pengobatan tulang tradisional dapat menimbulkan morbiditas yang tinggi seperti kehilangan anggota badan bahkan mortalitas.

Perlu dilakukan penelitian lebih lanjut dan dengan skala yang lebih luas untuk mengetahui secara pasti angka morbiditas dan mortalitas yang ditimbulkan oleh praktik pengobatan tulang tradisional dalam skala Regional dan Nasional.

\section{REFERENSI}

1. Ekere A.U., Echem R.C. Complication of Fracture and Dislocation Treatment by Traditional Bone Setters: A Private Practice Experience. The Nigerian health Journal. 2011. Oct-Nov; 11(4):1318.

2. Udosen A.M., Otei O.O., Onuba O. Role of traditional bone setters in Africa : Experience in Calabar, Nigeria. Annals of African Medicine.2006;5(4): 170-3.

3. Notosiswoyo M. Research on traditional bone healing in Cimande. Jakarta: Center of Noninfectious Research and Development, National Institute of Health Research and Development, $\mathrm{MOH}$, Republic of Indonesia; 1992.

4. Olaolorun DA, Oladiran IO, Adeniran A. Complication of fracture treatment by traditional bonesetter in southwest Nigeria. Farm Pract. 2001. Dec;18(6):635-7.

5. Dada AA, Yinusa W, dan Giwa SO. 2011. Review of the practice of traditional bone setting in Nigeria. Afr Health Sci. 2011 Jun;11(2):2625.

6. Alonge T.O, Dongo A.E. Traditional bone seters in South Western 
Nigeria-friends or foes? . WAJM.

2004. Jan-March; 23(1): 81-4.

7. Onuminya JE, Obekpa PO, Ihezue HC, Ukegbu ND, Onabowale BO. Major amputations in Nigeria: A plea to educate traditional bone setters. Trop Doct. 2000;30:133-5

8. Chika AT, Onyekwelu J. Traditional Bone Setter's Gangrene: An Avoidable Catastrophe, 8 Years Retrospective Review in Privare Orthopaedic and Trauma Centre in South-East Nigeria. The Nigerian Journal of General Practice. 2016. Jan-Jun;14(1) : 1-5.

9. Callisus K.B., Alhassan A, Issahaku M. Fracture Complications After Treatment by Traditional Bone Setters in Northern Ghana. Adv. Appl. Sci. Res. 2013. 4(6):207-211. 10. Wahyudiputra A.G., Khoirur H.D, Hakim R.A. Spektrum penderita Neglected fracture di RSUD Abdoer Rahem - Januari 2012 s/d Desember 2013. CKD. 2015. 225(42): 97-100. 